\title{
Musica Popular Rap: A Rima da Guerreira
}

Breitner Tavares ${ }^{*}$

Resumo: O objetivo deste trabalho é contribuir no contexto do debate acadêmico sobre a questão de gênero. Para isso, propõe-se realizar um estudo empírico sobre algumas orientações coletivas e da importância de estilos culturais para os grupos jovens e adolescentes, em especial aquelas "vítimas" da marginalização social, do masculinismo e discriminação racial. Nesse caso faz-se uma abordagem do que se conhece por Hip Hop, manifestação da juventude contemporânea que traz no seu interior a problematização de questões geracionais, bem como, aspectos vinculados às relações de gênero.

Palavras-chave: juventude, feminismo, racismo.

Abstract: This paper aims at contributing to academic discussions regarding the issue of youth and gender. We propose to carry out an empirical study about some collective orientations and on the importance of cultural styles for youth and adolescent groups, especially those who are "victims" to social marginalization, masculinism, and racial discrimination. In that respect, we approach what is known as Hip Hop, a contemporary youth manifestation that brings with it the problematics of generation issues, as well as aspects connected with gender relations.

\section{Key words: youth, feminism, racism.}

\section{Apresentação}

O objetivo deste trabalho é contribuir no contexto do debate acadêmico sobre a questão de gênero. Para isso, propõe-se realizar um estudo empírico sobre algumas orientações coletivas e da importância de estilos culturais para os grupos jovens e adolescentes, em especial aquelas "vítimas" da marginalização social, do masculinismo e discriminação racial. Nesse caso faz-se uma abordagem do que se

Latitude, vol. 6, n¹, pp.83-104, 2012

DOI: https://doi.org/10.28998/2179-5428.20120107 


\section{Musica Popular Rap: A Rima da Guerreira}

conhece por Hip Hop, manifestação da juventude contemporânea que traz no seu interior a problematização de questões geracionais, bem como, aspectos vinculados às relações de gênero.

Atualmente, o campo de produção artística em torno do hip hop avança rapidamente, no sentido de sua estruturação, reflexo da produção de vários grupos amadores. Gradativamente surgem grupos femininos que alcançam um lugar de destaque na indústria cultural.

Em termos metodológicos, observa-se que há vários grupos de rap femininos representativos nacionalmente como no eixo Rio de Janeiro - São Paulo, como a rapper Nega Gizza (RJ) e Dina Dee do grupo Visão de Rua (SP), Minas da Rima (MG), Atitude Feminina (DF) entre outras. Contudo, nesta abordagem é enfocada a manifestação no que se refere ao Distrito Federal, por ser significativa nos termos desta representação jovem no cenário Hip Hop em especial, pelo pioneiro trabalho desenvolvido por Vera Verônika.

É feita a análise de conteúdo de suas letras, matérias na impressa e trechos de depoimentos feitos em entrevista com o propósito, de discutir o problema de como o rap feminino estabelece discursos representativos do imaginário social de gênero.

\section{A categoria Juventude e a ausência feminina}

Ao se remeter à categoria juventude, objeto de diversas conotações, se faz uso do conceito de gerações desenvolvido por Mannheim (1980), o qual se refere de uma maneira geral, a uma noção qualitativa de tempo. Diversa, frente à subjetividade de seus atores, a juventude se realiza na busca de suas metas íntimas, do espírito de seu próprio tempo. Nesse caso o que importa é analisar quais são as intenções desses grupos.

A juventude de fato exprime reações diferentes frente a problemas semelhantes, observáveis nos diferenciados estilos de vida manifestos em especial na modernidade.

Ao recuperar o debate sobre a juventude em Mannheim, Weller (2005) retoma a perspectiva de tempo subjetivo, no qual a juventude vive a "não contemporaneidade dos contemporâneos", aquilo que permite o processo construtivo de novos sentidos dinamizadores das relações sociais. Cada geração, portanto, estabelece seus objetivos, os quais estão interligados ao espírito do tempo definido como o "inteléquio geracional". Mannheim (1980), apesar de não se vincular a uma interpretação mecânica do tempo, entende que a reação do biológico ocorre em função dos acontecimentos sociais que definem aspectos da posição, conexão e unidade geracionais. 
Breitner Tavares

A juventude participa do destino de uma unidade histórico social com seu potencial de aquisição de experiências em comum. Neste contexto, são reunidas diversas conexões da ação social, que podem ser observadas em termos de classe, gênero, raça e etnia.

Finalmente, o que é relevante para Mannheim (1980) é a análise de quais são essas intenções dos grupos, que reagem de formas diferenciadas diante de um mesmo problema, nesse tempo que é construído e (re) significado permanentemente.

Apesar de seu potencial analítico, a categoria juventude seguiu uma tradição "universalista" em termos de suas abordagens empíricas. Pouco foi empregada em estudos relativos ao gênero e em especial sobre jovens do sexo feminino. Weller (2005) argumenta que uma maior inserção de várias áreas no que se refere aos estudos sobre as culturas juvenis contemporâneas, reavaliando a noção de juventude para uma superação de uma compreensão "pré-social" restrita a uma base biológica como fator determinante de uma "crise" no processo de transição para o mundo adulto. "Se quisermos entender o que vem a ser juventude e como ela é vivida de fato pelos adolescentes e jovens de ambos os sexos, será necessário dedicar maior importância às descrições e narrativas dos atores envolvidos associada à reflexão teóricometodológica e à análise rigorosa dos dados empíricos ${ }^{1 "}$.

\section{Feminismo e racismo}

A mulher tem historicamente buscado se firmar enquanto sujeito social diferenciado com suas demandas e reivindicações, as quais, são diversas frente a uma opressão ao mesmo tempo universal. A questão feminista parte da afirmação de ser a identidade feminina socialmente produzida. A luta política das mulheres deve ser no sentido transformador das formas opressivas à mulher. Essa luta pela afirmação, contudo não é uma realidade homogênea e monolítica, mas vive na concretude das diferenças sociais e culturais que a constituem.

Ao se remeter a questões relativas a etnicidade e raça observa-se que novas configurações de feminismo se tornam visíveis. A origem ocidental do feminismo vinculado a aspectos da inserção social da mulher através da lógica da produção priorizou aspectos das relações de classes que não reconheceu no seu interior a

${ }^{1}$ WELLER, Wivian. A presença feminina nas (sub) culturas juvenis: A arte de se tornar invisível in Estudos Feministas, Florianópolis, 13(1): 2005, pág 7.

Latitude, vol. 6, n¹, pp.83-104, 2012. 


\section{Musica Popular Rap: A Rima da Guerreira}

diversidade que a categoria mulher representa. No Brasil da mesma forma o feminismo sofreu a influência eurocêntrica que motivou aspectos relativos à democracia racial e o ideal de branqueamento. Omitiu-se a centralidade da questão da raça presentes nas hierarquias de gênero ao universalizar os valores de uma cultura particular ao conjunto das mulheres, sem mediá-los com os processos de dominação, violência e exploração que estão na base da interação entre brancos e não brancos. "Por sua vez, também revela um distanciamento da realidade vivida pela mulher negra ao negar toda uma história de resistência e de lutas, nas quais essa mulher tenha sido protagonista graças a uma memória cultural ancestral". ${ }^{2}$

Sueli Carneiro (2005) chama atenção para a diferença histórica vivenciada pelas mulheres negras. Essa diferença diverge do mito da fragilidade atribuído normalmente a mulher de modo generalizado. Essa interpretação contribui para a omissão de aspectos precisos da violência sofrida pela mulher negra.

De que mulheres se está falando? Nós mulheres negras formamos parte de um contingente de mulheres provavelmente majoritário, que nunca reconheceram em si mesmas este mito, porque nunca foram tratadas como frágeis. Somos parte de um contingente de mulheres que trabalharam durante séculos como escravas lavrando a terra ou nas ruas como vendedoras ou prostitutas. Somos parte de um contingente de mulheres com identidade de objeto. Ontem, a serviço de frágeis senhoritas e nobres senhores tarados. Hoje, empregadas domésticas das mulheres liberais ${ }^{3}$.

Para superação do imaginário que localiza a mulher como uma "antimusa" as feministas negras propõem uma análise e gênero vinculado a outros eixos causadores da opressão. Em sociedades multirraciais, como as latino-americanas um desses principais eixos articuladores da interdição da mulher enquanto sujeito social ativo, é o racismo que estabelece assimetrias nas relações de gênero. $O$ feminismo negro objetiva redesenhar o campo de ação política das mulheres, ou seja, problematizar as contradições advindas das relações sociais de raça, classe e gênero. Essas categorias foram abordadas outrora de maneira fragmentária pelo movimento negro e pelo

\footnotetext{
${ }^{2}$ González citada por Bairros, 2000, pág 57.

${ }^{3}$ CARNEIRO, Sueli, Ennegrecer al feminismo La situación de la mujer negra en América Latina desde uma perspectiva de gênero, In CURIEL, Ochy,FALQUET,Jules, MASSON, Sabine Nouvelles Questions Féministes. Feminismos disidentes Volumen 24, No 2, Edición especial en castellano América Latina y el Caribe, Ediciones fem-e-libros www.creatividadfeminista.org, 2005, pág 22/23. Tradução feita pelo autor.
} 
Breitner Tavares

movimento feminista. "Enegrecer o movimento feminista e feminizar o movimento negro" 4 .

\section{Hip hop na Diáspora negra}

O Hip Hop, em termos gerais, se refere ao movimento cultural, produzido por jovens negros, surgido em espaços segregados de grandes metrópoles nos Estados Unidos no final dos anos sessenta por intermédio da influência $d u b^{5}$ da cultura caribenha que chegava aos EUA trazida por imigrantes. Atualmente é uma manifestação difundida mundialmente, que engloba estéticas artísticas como rap (musicalidade), o break (dança de rua) e o grafite (pintura aerográfica). O hip hop, desde de sua origem, tem sido associado, a uma arte voltada para segmentos excluídos no espaço urbano, como jovens, imigrantes, negros, mulheres, entre outros.

Paul Gilroy (2001) intelectual negro e britânico se remete à categoria diáspora como uma proposta para estudos culturais, com o objetivo de explicar a formação de uma cultura vernacular do Atlântico Negro. Em sua obra, o autor analisa o estabelecimento de mecanismo de distinção cultural adaptadas às novas circunstâncias do Reino Unido. Manifestações que atuam em separado e ao mesmo tempo em convergência. Gilroy(2001) atesta que o povo negro se recria enquanto grupo conglomerado, ao reinventar sua própria etnia. A retórica do poder negro é desvinculada de seus marcadores étnicos. Diante de sua condição de explorado passou a adaptação frente á suas necessidades locais e políticas, suas histórias de lutas.

O povo negro estabeleceu novas linguagens políticas de cidadania voltadas para a justiça racial e igualdade. Essas linguagens ultrapassaram a esfera da tradicional luta pelo trabalho e passaram também a se articular através do lazer. A diáspora permitiu a "transferência" de formas culturais e estruturas de sentimentos no que Gilroy(2001) chamou de "historicismo popular". O autor recorre à contribuição histórica da música negra para reconstruir essa trajetória estética e política da modernidade. Essa mesma história da qual se originará o hip hop e suas respectivas manifestações. De certa forma essa manifestação cultural corresponde a esse processo diaspórico de resignificação, de agenciamento da luta, da inserção social do negro por meio da ludicidade e da estética.

${ }^{4}$ CARNEIRO, Sueli, id.

${ }^{5}$ Música instrumental combinada com efeitos eletrônicos. 


\section{Musica Popular Rap: A Rima da Guerreira}

\section{Hip Hop e Misoginia}

O hip hop representa a partir de sua estética pós-modernista, propostas políticas, um tipo de arte social, com apelos frente à questão de exclusão social (classes), marginalização no espaço urbano (imaginário da periferia), a questão da segregação racial e, mais recentemente, à questão de gênero. No hip hop e em especial no rap ${ }^{6}$ há todo um discurso voltado para o jovem das classes sociais populares e em especial para o negro, configurando um meio de expressão afirmativa. Contudo, mesmos os estudo pós-coloniais como os enunciados por Gilroy (2001), atesta-se para a conotação misógina e masculinista que expressa uma relação de conflito entre homens e mulheres (negros e negras) no contexto norte americano. No Brasil um dos grupos mais relevantes da cena contemporânea do rap nacional: os Racionais MC's de São Paulo, apesar de sua preocupação com uma "crônica social" e a mobilização da juventude negra das periferias, marcaram de modo enfático o aspecto sexista recorrente dentro do hip hop o que é exemplificado em faixas como: Mulheres Vulgares, Fórmula Mágica da Paz, Estilo Cachorro e Jesus Chorou:

\section{Mulheres Vulgares (1990)}

Exige direitos iguais(...) E o outro lado da moeda, como é que é? Pode crê! Pra ela, dinheiro é o mais importante. Sujeito vulgar, suas idéias são repugnantes. É uma cretina que se mostra nua como objeto. É uma inútil que ganha dinheiro fazendo sexo. No quarto, motel, ou tela de cinema. Ela é mais uma figura viva, obscena. Luta por um lugar ao sol. Fama e dinheiro com rei de futebol! (ah, ah!). Ela quer se encostar em um magnata. Que comande seus passos de terno e gravata (otário...). Quer ser a peça central em qualquer local. E a jura é total, Quer ser manchete de jornal. Somos Racionais, diferentes, se não iguais. Mulheres Vulgares, uma noite e nada mais! Mulheres... vulgares.

\footnotetext{
${ }^{6}$ Estilo musical integrante do hip hop que implica em cantar uma letra de maneira rítmica. Rap é um termo originário do inglês que significa rhythm and poetry. O cantor de rap é chamado rapper ou MC master of cerimony. O rap é normalmente acompanhado de bases rítmicas eletrônicas chamadas bases coordenadas pelo dj.
} 
Breitner Tavares

Mulheres vulgares, uma noite e nada mais. Mulheres... vulgares.

\section{Fórmula Mágica da Paz (1998)}

Nada de roupa, nada de carro, sem emprego, não tem Ibope, não tem rolê, sem dinheiro: sendo assim, sem chance, sem mulher você sabe muito bem o que ela quer encontre uma de caráter se você puder É embaçado ou não é?

Estilo Cachorro (2002)

Fale o que quiser

O que é...é

Verme ou sangue bom tanto faz pra mulher Não lhe importa de onde vem e nem pra quê Se o que ela quer é mesmo é sensação de poder Pergunte a Sansão quem foi Dalila (...) Mulher finge bem, casar é negócio você vê quem é quem só depois do divórcio hei neném de amor eu não morro vocês consagraram o estilo cachorro"

Jesus chorou (2002)

"Um piolho diz assim quando me vê: famoso pra caraio e durão... hi truta faz seu mundo não Jão, a vida é curta Só modelo por aí dando boi põe elas pra chupar e mandam andar depois rasgar as madrugadas só de 1.100 se sou eu truta, não tem pra ninguém"

Nessas letras, a mulher é generalizada como um indivíduo deslocado de uma conduta supostamente de "mulher de caráter", que recebe a proteção ativa de um 


\section{Musica Popular Rap: A Rima da Guerreira}

homem em contrapartida de uma posição hierarquicamente subalterna. A "mulher vulgar", a prostituta, do mesmo modo, está presente num contexto de relações de gênero estabelecidos de modo desigual. Sua aparente autonomia a submete a mecanismos de socialização e de relações econômicas que não lhe conferem "um lugar ao sol" ou "peça central" como considera Teixeira (2003) no que se refere à relação conflituosa da polícia em com as prostitutas em Brasília. De fato, os apelos misóginos contra a mulher adquirem múltiplas nuances, que constituem um sistema de estratificação, onde são localizadas as "mulheres vulgares" bem como as de "caráter".

Benhabib (1991) argumenta que o pensamento político liberal é desfigurado pela desigualdade e hierarquia presente na raiz das dicotomias consideradas legítimas. A concepção pública do "eu" como igual e abstrato portador de direitos é prejudicado pela desigualdade, assimetria e dominação que permeia a identidade privada desse "eu" como sujeito dotado de gênero.

A única exceção relativa à negatividade da mulher ocorre quando ela é associada ao papel, do mesmo modo naturalizado, de maternidade e ao trato da criança no contexto da ausência do homem-pai: Uma negra e uma criança nos braços Isolitária na floresta de concreto e aço (...) Aí dona Anal sem palavral a senhora é uma rainha(...) Nego Drama 2002. No que se refere ao problema da deserção da paternidade, a tese de Ana Liési Thuler(2004) trata do problema, como resultado da instituição patriarcal que além de despersonificar a mulher, isenta o homem da responsabilidade política e jurídica do papel social de "pai", condição que mantém a disseminação dos "filhos da mãe". A mulher se torna a "rainha do lar" na medida que assimila papéis essencializados dos quais em geral os homens se mantém à distância.

Todos os trechos, de apelo sexista, naturalizam a condição da mulher submetida a uma relação de status centrada no homem. Segundo Segato (2003), mesmo numa sociedade moderna supostamente articulada por relações de impessoalidade previstas num contrato social, relações de status continuam afirmando a condição de negatividade da mulher, seja no contexto da prostituição da mulher ou no contrato matrimonial incluindo seus atributos de maternidade e trato dos afazeres domésticos. O desvio das condutas subordinadas pode gerar, como conseqüência, castigos ou vinganças violentas contra a mulher, justificadas seja por uma subjetividade, ou mesmo, por regras jurídicas determinadas por uma ordem discursiva e produzida segundo condições estabelecidas historicamente nas relações de poder que incluem homens e mulher. 
Breitner Tavares

\section{Gênero e Raça e hip hop}

O discurso originário da emancipação racial negra tem entrado em certas ocasiões em dissonância frente à construção conflitiva da sexualidade. Parece cada vez mais inviável, uma separação destas questões raciais e de gênero, presentes nas articulações estratégicas advindas do repertório de procedimentos enunciativos do rap.

Os estudos multiculturais historicamente lidaram com a desconstrução da categoria "classe" de aspecto generalizante, ao afirmar que essa só poderia ser vivenciada por indivíduos dotados de "raça". A questão do conflito instaurado por um masculinismo no hip hop chama atenção para um outro aspecto a ser problematizado: "o gênero é a modalidade na qual a raça é vivida"7, em outros termos, o corpo é fator significante que dá lugar a conteúdos variados ao serem considerados observar questões de gênero desvinculadas dos aspectos de racialidade tende a incorrer num outro tipo de universalismo.

A diferença estabelecida pela raça constrói novas variantes simbólicas nas relações masculino e feminino, as quais, naturalizados no interior da vida familiar patriarcal e que da mesma forma reproduz referencias de identidades raciais, consideradas estáveis. "Essas identidades de gênero passam a exemplificar diferenças culturais que aparentemente brotam da diferença étnica absoluta. Questioná-las e questionar sua constituição da subjetividade racial é imediatamente ficar sem gênero e colocar-se fora do grupo de parentesco racial".$^{8}$

Finalmente, o hip hop permite a circulação em termos planetários do discurso de uma identidade racial como manifestação proveniente da diáspora africana que é agora reinterpretada sob configurações de gênero e sexualidade.

\section{Feminismo e hip hop: Mulher na Real ${ }^{9}$}

Apesar do número majoritário de grupos masculinos que polarizam a produção do gênero rap em termos nacionais e internacionais já é visível à participação de alguns grupos femininos profissionais, assim como, uma variada gama de grupos de jovens que participam de circuitos amadorísticos que se apresentam de um modo geral em pequenos shows em espaços públicos. Elas são patrocinadas por pequenos

${ }^{7}$ GILROY, Paul. O Atlântico Negro, Rio de Janeiro, UFRJ, 2001, pág 180.

${ }^{8}$ GILROY, Paul, id.

${ }^{9}$ Os depoimento utilizados nessa sessão foram obtidos no I encontro de Hip Hop organizado ocorrido no auditório do sindicato dos Professores (Sinpro- DF) em 29 de junho de 2003.

Latitude, vol. 6, n¹, pp.83-104, 2012. 


\section{Musica Popular Rap: A Rima da Guerreira}

empresários ou motivadas por atividades pedagógicas em escolas ou associações. Esses grupos oriundos de comunidades, em geral carentes, normalmente se afiliam a grupos comunitários de ação social de apoio à juventude. De fato, são inúmeros exemplos recorrentes no Brasil desses grupos como: Minas da Rima, Nega Gizza (RJ), Dina Dee (SP), Vera Verônika (DF), entre outros.

V: Hoje eu sou da minha época, de dez anos atrás, eu sou a única mulher que ficou, que canta rap. Graças a Deus a gente tem aí, treze grupos no Distrito Federal femininos. Estão meio escondidos e tal, vão assim, se apresentam em alguns lugares, quando o pessoal dá espaço, mas o espaço ainda é muito escasso é muito pouco.

Em Brasília ainda é relativamente recente, a mobilização das mulheres no hip hop. O próprio rap é um fenômeno que surge no cenário funk ${ }^{10}$ do início dos anos 90 com ênfase especial para o grupo Câmbio Negro de Ceilândia-DF. Neste período a participação de mulheres ainda é restrita como retratou recentemente o filme dirigido por Adirlei Queiroz Rap o canto de Ceilândia, premiado na categoria melhor documentário no Festival de Brasília do Cinema Brasileiro (2005). Foi retratado, na forma de documentário, o surgimento e a trajetória dos principais fundadores da cena local: X (equis), Jamaika e Japão. O filme mostra de maneira verossímil todo o contexto de contradições sociais que levaram ao surgimento de juventude que usou a arte do rap para denunciar todo um contexto de injustiças como a pobreza, a marginalização e o racismo. Contudo, ao ser questionado sobre a ausência de mulheres no filme, Adirlei argumentou que "de fato nesse período era praticamente inexistente a participação feminina no rap, só existiam 'os caras', o sexismo na verdade ainda é característico nessa cena. O rap é sexista11". As poucas pesquisas sobre a sub cultura hip hop no Distrito Federal como desenvolvidas por Amorim (1997) e Ferreira (2002) expressam essa manifestação de modo universalista sem considerar a relações de gênero entre homens e mulheres. Obviamente as relações de gênero já eram presentes na estética hip hop, contudo essa presença não significou que a mulher tinha uma interface

\footnotetext{
${ }^{10}$ Funk se refere nesse contexto a um ritmo musical eletrônico e majoritariamente norte americano que influenciou algumas gerações a partir dos anos 80. Sobre a cultura funk veja-se Hermano Vianna em Mundo funk Carioca, 1998.

${ }^{11}$ Depoimento obtido por ocasião de uma reunião, em dezembro de 2005, do Centro de Estudos Paulo Freire CEPAFRE em Ceilândia, na qual Adirlei Queiroz esteve presente para a exibição do Rap Canto de Ceilândia.
} 
Breitner Tavares

positiva. A mulher e a feminilidade eram objeto do masculinismo, postas em segundo plano.

Sofrendo inúmeras restrições, somente nos primeiros anos do século XXI, que é lançado o primeiro disco de rap gravado por uma mulher. Antes as minas só tinham pequenas participações em algumas coletâneas ou assumindo o posto secundário de backing vocal. Muitas são as dificuldades daquelas que buscaram inserção na cena rap brasiliense como relatam a jovem Verônika cantora de rap e moradora da região do Entorno do Distrito Federal da cidade de Valparaíso (GO), que gerou a aproximação de membros da cena que, em alguma medida, lhe permitiram o acesso:

$\mathrm{V}$ : A gente quase não vê mulher cantando, mulher dançando. Mas existem as revolucionárias. Eu comecei a curtir rap porque eu via as pessoas se movimentando, isso me deixava alucinada. Eu não cresci ouvindo rap, mas aquela música me chamava à atenção. Tudo na vida deve ser feito com base na informação. Aí eu fui ler. Conheci uma pessoa chamada Dino Black, que foi um livro na minha vida. Eu vou cantar rap isso vai ser legal na minha vida. Como é que canta rap? Meu Deus. Como é que escreve? Como é que faz base?

O rap com toda sua configuração enquanto linguagem artística demanda o conhecimento de certos rudimentos, códigos de acesso que se expressam no maneirismo rítmico com as palavras, nas composições das letras, bem como do domínio técnico de recursos de mixagem de efeitos sonoros chamados "base".

Verônika narra a sua trajetória que envolveu a aproximação de homens até então detentores do conhecimento dos elementos estéticos do rap. Assume-se enquanto "ameaça" num ambiente onde a representação feminina era ausente, algo que interferia na adesão e mobilidade em meio aos grupos e eventos produzidos por homens.

$\mathrm{V}$ : E nesse meio tempo procurava homens que cantavam rap. E as portas só se fechavam. Como é que escreve, como é que faz base...Na época que eu comecei eu era uma ameaça. Uma mulher com uma voz grossona. Causava maior impacto quando eu cantava. E aí... como é 


\section{Musica Popular Rap: A Rima da Guerreira}

que se fazia uma base? Ninguém me falava...como se fazia uma base. Ninguém deixava eu cantar nos shows.

Pra eu cantar eu ligava e azarava o cara a semana inteira. "Pô bixo deixa eu tocar lá. Só um som, eu faço só a introdução, e páh!... E aí ninguém me ensinava como é que fazia base. Aí eu aprendi a editar fita. Sozinha! Editava errava, editava a fita, e aprendi a editar a fita, e aprendi a editar a fita. Eu mesma produzia minhas bases.

Ao se referir ao tom misógino do hip hop, Verônika recorre ao termo monopólio pra expressar a situação de interdição e dificuldades que vivenciou, segundo ela, nos três primeiros anos de seu envolvimento, em um mundo até então masculino. Ela também chama atenção nesse contexto para alianças com outras mulheres que também foram significativas para promover uma afirmação feminina:

V: Aí tinha uns caras e falavam: "Como tu é chata eu vô te ensinar vô fazê uma fita pra você." Aí vinha um outro, fazia uma base, não dava certo com a minha levada. Eu nem sabia o que era "levada", pro jeito que eu cantava. E nisso, os três primeiros anos foram muito difíceis. Porque $\mathrm{o}$ monopólio do hip hop. Eu chamo de "monopólio". Quem detém o poder naquele momento de show, de rádio, de produção. Eles não abriam a porta pra mim. Aí eu conheci uma muleca muito doida. Que passou na minha vida. Ela conhecia muita gente. Aí as coisas foram caminhando, devagar. Aí a gente conseguia fazer base, mas tudo também era de graça. Ninguém trabalhava. Ne? Todo mundo era estudante. Ai eu fui pelejando. Os três primeiros anos foram árduos e muito difíceis, mas eu não desisti.

O rap significava mais que o domínio de técnicas de canto das levadas ${ }^{12}$ ou a participar de shows. O rap tinha um significado pedagógico, ao mesmo tempo lúdico, um potencial para a mobilização comunitária:

$\mathrm{V}$ : Nesse meio tempo eu comecei a abstrair alguma coisa do rap, a não ser os shows aquelas coisas...E eu comecei junto com minha mãe a pegar menino na rua. Via um

\footnotetext{
${ }^{12}$ Levada se refere à maneira de condução do canto que costuma ser rimado.
} 
Breitner Tavares

menino na rua... "Vamos levar pra casa". Hoje eu tenho um orfanato com vinte e seis crianças. E se bater mais um na porta, entra.

E o que eu tenho pra dizer sobre a mulher no hip hop, é que muitas desistiram, mas eu to aí. Pra provar que é um movimento forte e decisivo e que pode mudar a vida das pessoas, se elas quiserem também, né? Por que muita gente fala assim: "Eu vou mudar! Eu vou revolucionar! Eu vou corre atrás!" Mas fica ali. Não se movimenta pra isso.

Fica aberto pra quem quiser trocar idéia.

Verônika fala da sua experiência enquanto estudante, e chama sutilmente a atenção para as relações raciais vividas por uma mulher negra num espaço majoritariamente ocupado por brancos, como é o espaço universitário. A estigmatização racista não impede a reação através de estratégias de compensação por atributos de mérito intelectual e acadêmico:

V: Me formo este ano em pedagogia. Foi muito difícil entrar nessa faculdade, porque eu sou a única mais escurinha que tem lá. É uma faculdade particular. Lá eles dizem que eu sou "escurinha" né? Eu sou a única mais escurinha que tem lá. E eu faço essa faculdade através de uma bolsa. Que a cada três meses eles me testam. Eu faço uma prova pra poder continuar com essa bolsa. É até uma coisa injusta. Porque essa prova deveria ser semestral, mas eu faço trimestral, mas eu faço. A gente tá ai pra isso, pra correr atrás dos objetivos. Me formo esse ano em dezembro. Não vou poder participar da formatura, porque pelo fato de ser uma faculdade particular, a formatura por formando ficou $\mathrm{R} \$ 5000,00$. E por ai vai.

\section{A poética é feminina}

O rap em alguns momentos se constitui num estilo musical que está centrado no conteúdo do discurso que é expresso nas letras. Naturalmente aspectos relacionados às bases e efeitos sonoros criarão a atmosfera que, em geral, deve estar 


\section{Musica Popular Rap: A Rima da Guerreira}

em consonância com as rimas e a "idéia" da letra. O público, fica atento ao que está sendo cantado, procurando compreender sua mensagem.

O álbum lançado no circuito independente: Vera Verônika canta MPB-RAP lançado em 2005 constitui um marco no que se refere à produção artística e além de reunir os principais expoentes da cena rapper do Distrito Federal como DJ Jamaika, $X$ (equis), Gog, Dino Black entre outros. Estes homens produziram faixas especialmente para este trabalho.

O disco conta com 26 faixas, com a participação de vários grupos. Nele as questões recorrentes, no rap como a pobreza, exclusão social, racismo, estão presentes. O que diferencia este trabalho dos demais é a presença da mulher num tom afirmativo. Logo no encarte se refere a sua origem e dificuldades enfrentadas pela exclusão racial.

A candanga negra, solteira, com família toda brasileira, com mãe e irmãos sem direito ao tão sonhado teto, fomos expulsos, abandonados e jogados ao relento da ilusão. O pouco que tínhamos não dava para um aluguel decente e a invasão não ${ }^{13}$.

A faixa introdutória intitulada Mulher apresenta aquela que se auto representa e é autora de seu próprio discurso e representação.

Destino da favela o unindo a gente vira.

Verônika na barca, palavras com rima.

Batendo de frente sou mulher da real.

Atitude nos versos rap nacional.

O rap entendido como uma forma lúdica de pedagogia, como uma oportunidade para difusão de propostas que extrapolam o contexto da representação artística. A arte social do rap divulga instituições que, de alguma forma, estão vinculadas às propostas sociais eleitas pelos participantes do cenário juvenil. Nas músicas guerreira e mulher são enfatizados o trabalho da instituição de amparo a criança Recanto da Paz localizada na região do Entorno do Distrito Federal em Valparaiso - GO. Esta casa foi criada e mantida por Verônika e sua mãe dona Diana.

${ }^{13}$ Texto presente no encarte que acompanha o álbum : Verônica Canta MPB RAP, 2004. 
Breitner Tavares

\section{Mulher}

Deus abençoe todas as quebradas e o Recanto da Paz Lar para crianças abandonadas e hoje amparadas Pode crê mãe Diana estou contigo nessa caminhada.

\section{Guerreira}

Recanto da Paz uma casa aberta a criança sem lar sem pai sem ninguém dona Diana abençoada e amada por todos em meio as dificuldades

Falta de grana não deixa a peteca cair nem o feijão queimar

Graças a deus que inventaram a farinha pro tutu render e se multiplicar

Neste lar quantos baterem na porta vão entrar.

Agradeço em particular

Pela rainha do meu lar

O exemplo mais puro do amor verdadeiro que continua a caminhada conosco

O nome de dona Diana é em alguma medida associado, à idéia de mãe, que traz consigo uma série de atributos como é expresso na música guerreira. Nessa faixa cabe considerar, além de aspectos textuais da letra, a densidade que adquire ao recorrer a um fundo musical que é utilizado na mixagem. Trata-se da música Ave Maria de Schubert interpretada por Gounot, o qual se remete ao sentido da oração cristã de culto ao mistério da maternidade.

\section{Guerreira}

De uma hora pra outra mudam o tom da vida Através do sofrimento e das angustias vividas Sei que clamam uma trilha melhor pros filhos teus Mãe minha que chora a ver-me chorando

Só ela já sabe o que já passou na gestação

Na falta de um pai, de um pão

Enfrentou desafios barreiras, fome, frio, tristeza 


\section{Musica Popular Rap: A Rima da Guerreira}

Pra manter-me de pé olho pra traz e vejo o quanto ela perdeu, mas não se arrependeu da dor

Graças a Deus tudo ela superou

Há vários corações cheios de tristezas

Marcados por sofrimento e pobreza

Pois é nela que se processa o ministério da vida

É nelas que se afirma a maturidade do homem

A vos suspiramos vivendo e chorando

Neste vale de lágrimas

O tom de denúncia da violência e o abandono, temas recorrentes no rap, são abordados pela problemática de gênero centrado na imagem da mulher, a qual é submetida a maternidade. Um aspecto relevante na interação que existe entre os cantores de rap é o tom de "desafio" ou simplesmente "diálogo" através da música. O tema da prostituição, de certa forma, surge no rap nacional pela perspectiva misógina. Aqui ocorre uma resposta a essa misoginia, uma construção que esboça a prostitutamãe "bendita", em detrimento da prostituta, como simplesmente parte das "mulheres vulgares".

\section{Guerreira}

Mas pelas mães imaturas que deveriam estar brincando com bonecas e não com bebês.

São as crianças que vem sem pai sei lá.

Sem ninguém, pois as mães que estão parindo são crianças também.

Que os frutos vençam os desafios.

E deixem vir flores entre os espinhos.

Benditas sejam as prostitutas mães das vidas

Sois vós entre as mulheres

Bendito seja vosso fruto que te dará razão pra viver.

Em outra faixa Heroína o tema da prostituta pela perspectiva da "sina" resultado de relações de gênero desiguais produzidas pelo machismo e pelo racismo que localizam a mulher negra num papel social, dentro do sistema produtivo, que a "ilude" no que considera "indecência" e "vergonha". O sentido da categoria ilusão de 
Breitner Tavares

certa forma também se distancia da concepção que naturaliza o sentido de "mulheres vulgares" ou das "Cachorras".

Heroína

De correria em correria

Luta pra mudar sua sina de prostituição a profissão mais antiga dos tempos

Mas mais antiga ainda é a missão de ser guerreira sobreviver em uma sociedade machista

Onde você mulher é a real vítima da piedade e da recessão

Exploradores da prostituição

Miséria e ambição maldita

È uma vergonha pro país

Uma indecência

E a droga é fonte de sua decadência

Não pretendemos perder tempo difamando mulheres vulgares

São apenas iludidas com o sistema que nelas implantaram

Estão desmotivadas a progredir num trampo decente

Sem perspectiva de uma vida contente

Você não é objeto e muito menos animal

Seu valor de mulher negra não se paga em real

A noite uns tais manos vão pegar umas cachorras

Se você é um ser humano não se enquadra nesse plano.

Nesta faixa a categoria "mulheres vulgares" é empregada numa perspectiva diversa da imposta pelos rappers dos Racionais MC's. A condição de prostituta é vista como mais um contexto de segregação sofrida pela mulher ao longo de um processo de socialização que fazem das mulheres prostituídas "desmotivadas a progredir num trampo decente". Estabelecer uma linha discursiva sobre a prostituição além de se vincular ao caráter de denúncia característico do rap-nacional se constituiu numa resposta contra o sexismo presente no hip hop desde seus primeiros tempos. Na faixa heroínas, essa "mulher vulgar" adquire uma nova densidade quando sua raça é 


\section{Musica Popular Rap: A Rima da Guerreira}

referida. A mulher negra que historicamente foi identificada dentro de um sistema de estratificação, onde a "mulata" simbolizada como esse objeto de sensualidade tem menos autonomia que a mulher branca. A música em questão diverge dessa assertiva duplamente sexista e racista ao afirmar que, "você não é objeto e muito menos animal. Seu valor de mulher negra não se paga em real".

O disco Veronika Canta MPB Rap, além de convergir músicos já consagrados do cenário local, com faixas voltadas para a valorização da mulher dentro do hip hop, traz em várias faixas a participação de outras mulheres que estão vinculadas à posse categoria advinda do $\mathrm{MNMMR}^{14}$ que se refere à mobilização das mulheres no rap pelo resgate de valores, dando dignidade, integrando o jovem à sociedade. A música Destino, que reúne 13 grupos de rap feminino do Distrito Federal e Entorno, com refrão de Vera Verônika e Anny Toledo: Execução Sonora, Digelaine, Foras da Lei, De Igual pra Igual, Atitude Feminina, Minas Blindadas, Aliadas de Rua, Ana, DJ Dona, Michelle, R-Dy, Gandra e Luara 10zero4. Essa faixa exprime uma grande densidade, pois as várias rappers apresentam múltiplas formas rítmicas e melódicas do estilo, assim como múltiplas feminilidades.

Destino

Não tem tapete vermelho pra guiar o meu discurso

$(. . .)^{15}$ pela verdade o rap eu me dediquei

Quatro anjos da favela, mulheres: as fora da lei

(...) de saia (...)revolta do feminino

do (...) infinito entre os sonhos e as maldições do destino

O espelho do absurdo refletem imagens na escuridão

(...)Resistem(...) contra a maldição

Ser mulher, ser amante (...)

Por natureza

Uma guerreira de uma correria dar de beleza

Avante companheira de cabeça erguida(...) no lado do seu caminho

Quem nasce no signo da luta tem o dom de mudar seu destino.

\footnotetext{
${ }^{14}$ Movimento Nacional de Meninos e Meninas de Rua se refere a uma entidade criada nos anos oitenta que tem como principal foco a defesa de jovens vítimas da exclusão social.

${ }^{15}$ Esses sinais (...) indicam trechos em que não foi possível realizar a transcrição das músicas. Indicam "lacunas".
} 
Breitner Tavares

As letras do álbum em geral estão voltadas à valorização da "mulher" enquanto a "guerreira". Letras que se referem diretamente à categoria "homem" ou ao "machismo" são pouco recorrentes. A afirmação, como em Heroína está associada a uma crítica de tom visceral direcionada à categoria do homem sexista, "os animais", o interlocutor de uma relação de gênero conflituosa.

Heroína

Se revele, se descubra

Sina de mulher

Que desponta é a luta

O suor na testa

O troféu da mulher

Heroína é assim que é

Fechamos os nossos olhos

Calamos a nossa boca

Nunca foi protegida

Acabamos no desamparo

E nos apontam que o contrário

Como se fossemos rivais

Me refiro aos verdadeiros animais

Quer que sejamos indefesas diante de sua opressão

Submissa excluída sem chance de reação

Seria tão fácil esquecer o passado que conquistamos

Mas continuam nos apunhalando

Não tem nada de agradável ser discriminada

Com o correr do tempo conquistamos o pouco que hoje temos

$\mathrm{O}$ acesso a cidadania

Celebrar letras marcadas pelo sofrimento, seria o suficiente mas não o bastante pra se contentar

Guerreiras que superaram barreiras para serem honradas

Latitude, vol. 6, n¹, pp.83-104, 2012. 


\title{
Musica Popular Rap: A Rima da Guerreira
}

\author{
Pois a discriminação o desajuste a rejeição se faz \\ presentes \\ Ser mulher mãe solteira e negra \\ Nos torna indigentes de uma sociedade totalmente \\ carente \\ Minha pele escura é uma questão de nobreza \\ Pois sou guerreira mulher mãe solteira em meio a \\ pobreza \\ Conquistando um espaço que há tempos nos foi \\ negado
}

Nos estudos de gênero como apresentados por Segato 1997 o corpo, a anatomia propriamente dita, e a maneira como se inscreve na auto-percepção constitui algo fundamental. O corpo atua como significante, dá lugar a conteúdos variados segundo as culturas (gênero e personalidade). $\mathrm{O}$ hip hop feminino trabalha um novo campo discursivo em relação à corporeidade da mulher. Essa mulher que é jovem, negra e mãe é convidada a "se revelar" a se "descobrir". Em Heroína há uma clara separação, da disposição sexual centrada em relação a um sistema de status diferenciados, proveniente de estrutura patriarcal e racista. A mulher negra, jovem mãe solteira tem a possibilidade de assumir papeis sexuais ativos ou passivos em sua interação sexual. A "guerreira" e "heroína" em meio à pobreza reinterpreta "sua sina de mulher" para além de uma liberdade civil que não é de fato universal, mas um atributo masculino dependente do direito patriarcal com é analisado por Pateman (1993). A mulher proposta em Heroína é tributária da mobilização pelos valores igualitários e individuais historicamente reconhecidos pelos movimentos sociais feministas, pela inclusão de categorias como raça, e classe na relação com as problemáticas enfrentadas pelos jovens envolvidos no hip hop.

\section{Considerações Finais}

O hip hop enquanto um bem simbólico produzido no contexto da produção estética da juventude negra na modernidade trouxe aspectos de reconstrução e positivação dos negros e excluídos. A questão de gênero, e especificamente da misoginia presente em relações desiguais da juventude, ou a uma nova mobilização que contemplasse respectivamente as demandas de atores sociais contrários ao racismo e ao sexismo. 
Breitner Tavares

As ciências sociais pouco produziram no que se refere à questão da juventude em pesquisas empíricas que observem aspectos de gênero e sexualidade em relação às categorias raça e gênero. O contexto da produção de um cenário artístico do rap em Brasília traz vários desdobramentos dessas relações de gênero e raciais, as quais ainda não foram abordadas de modo conclusivo. $\mathrm{O}$ caso da mulher no hip hop apresentado na análise do trabalho Vera Verônika expõe parte desse universo em transformação da modernidade pela inserção da mulher negra que se opõe numa dupla frente antimasculinista e anti-racista.

\section{Referências}

AMORIM, Lara Santos. Cenas de Uma Revolta Urbana, Movimento hip hop na periferia de Brasília, Brasília Dissertação de Mestrado pelo Departamento de Antropologia da Universidade de Brasília. 1997.

BENHABIB, Seyla e CORNELL, Drucilla. Feminismo como crítica da Modernidade. Rio de Janeiro, Rosa dos Tempos, 1991.

BANDEIRA, Lourdes e SIQUEIRA, Deis. A perspectiva Feminista no Pensamento Moderno e Contemporâneo. In: Revista Sociedade e Estado, XII/2, Brasília,1997.

BAIRROS, Luiza. Nossos Feminismos Revisitados In: Revista Estudos

Feministas. Río de Janeiro: IFCS/UFRJ - PPCIS/UERJ . Vol. 3 N.2/95

Lembrando Lélia Gonzalez. In: O livro da saúde das mulheres

negras. WERNECK, Jurema (org.) et alii.. Rio de Janeiro: Pallas-Criola, 2000.

CARNEIRO Sueli, Ennegrecer al feminismo La situación de la mujer negra en

América Latina desde uma perspectiva de gênero, In CURIEL,

Ochy,FALQUET,Jules, MASSON, Sabine Nouvelles Questions Féministes.

Feminismos disidentes Volumen 24, No 2, Edición especial en castellano América

Latina y el Caribe, Ediciones fem-e-libros www.creatividadfeminista.org, 2005.

FERREIRA, Erika do Carmo Lima. Voses e Identidade Juvenil, Dissertação de Mestrado, Departamento de Letras, Universidade de Brasília, 2002.

FORMAN, Murray. Black feminist theory, standpoint, and women in rap.

Gordon and Breach Science Publishers S.A. (UK) 1994

FOUCAULT, Michel. A História da Sexualidade, Volumes I, II, III. Rio de Janeiro, Ed. Graal, 1984.

Latitude, vol. 6, n¹, pp.83-104, 2012. 


\section{Musica Popular Rap: A Rima da Guerreira}

GILROY, Paul. O atlântico negro. Modernidade e dupla consciência. Rio de Janeiro: $\quad$ UCAM, São Paulo, Editora 34, 2001.

HOLLANDA, Heloisa Buarque de. Tendências e Impasses. O Feminismo como crítica da cultura. Rio de Janeiro, Rocco, 1994.

MANNHEIM, Karl.Strukturen des Denkens. Frankfurt a. M.: Suhrkamp, 1980.

PATEMAN, Carole. O contrato Sexual. São Paulo, Paz e Terra, 1993.

RODRIGUES, Marlete Teixeira. Polícia e Prostituição feminina em Brasília - Um estudo de caso. Tese de doutorado, Departamento de Sociologia, Universidade de Brasília, UnB, 2003.

SEGATO, Rita Laura, Lãs estruturas Elementares de la Violência, Ensayos sobre gênero entre la antropologia, el psicoanálisis y los derechos humanos. Quilmes. Ed. Universidade naciolnal de Quilmes, 2003.

THURLER, Ana Liési. Paternidade e deserção: Crianças sem reconhecimento, maternidade penalidades pelo sexismo, Tese de doutorado, Departamento de Sociologia, Universidade de Brasília, UnB, 2004.

VIANNA, Hermano. Mundo Funk Carioca, Rio de Janeiro, Ed. Zahar, 1988.

WELLER, Wivian. A presença feminina nas (sub) culturas juvenis: A arte de se tornar invisível in Estudos Feministas, Florianópolis, 13(1): 2005.

A atualidade do conceito de gerações de Karl Mannheim: perspectivas para a análise das relações entre educação e trabalho. Caxambu, XXIX Encontro Anual da ANPOCS, 2005.

\section{Discografia:}

Racionais MC

Holocausto Urbano -1990

Sobrevivendo No Inferno - 1998

Nada Como Um dia Após Outro Dia -2002

\section{Vera Verônika}

Vera Verônika Canta MPB-Rap-2004.

\footnotetext{
* Doutor em sociologia pela Universidade de Brasília- UnB, Brasil. Membro do grupo de pesquisa Educação e Políticas Públicas: gênero, raça/etnia e juventude - GERAJU e Cidades e Sociabilidades, ambos na Universidade de Brasília. Professor da UnB-FCE curso de Saúde Coletiva. btavares@gmail.com.
} 